\title{
Flux Prediction in Direct Contact Membrane Distillation
}

\author{
Dahiru U. Lawal and Atia E. Khalifa
}

\begin{abstract}
Membrane distillation (MD) is a potential mean of water desalination. MD is a thermally driven desalination technology that has been employed in four basic configurations. One of these configuration is Direct Contact Membrane Distillation (DCMD). In DCMD, both hot and cold solution is maintained in direct contact with micro porous hydrophobic membrane material. Heat and mass transfer analysis was performed on DCMD. Based on Kinetic theory of gas, the performance of different models of membrane permeability (coefficient) was investigated under different DCMD operating parameters (feed temperature, coolant temperature and feed flow rate). Knudsen number provides the guideline in identifying the type of model of mass transfer to be considered under any given experimental conditions.

Results revealed that for a given pore size under the same simulation and experimental conditions, Transition (KnudsenMolecular diffusion) type of flow model predictions is in good agreement with the experimental results. Hence the best model to be consider for flux prediction in DCMD. The effect of membrane pore size was also studied. Results showed that permeate flux increases with increase in pore size up to the critical pore condition where the flux prediction remain constant (unchanged).
\end{abstract}

Index Terms-Desalination, direct contact membrane distillation, flux prediction, hydrophobic membrane material.

\section{INTRODUCTION}

Membrane distillation (MD) is an emerging technology for desalination. It is a thermally driven separation process in which separation is achieved as a result of phase change. Membrane distillation is a process that applied differences in vapour pressure to permeate water vapour through hydrophobic membrane sheet and reject non-volatile component present in the water. A.S Jonsson et al. [1] stated that Findley was the first to link the separation techniques now known as membrane distillation (MD). Membrane distillation differs from other membrane technologies since the driving force for desalination is not the total pressure of water through the membrane but the difference in vapour pressure of water across the membrane.

The membranes materials usually employed for MD are hydrophobic in nature. Four basic configurations are usually employed in MD [2]. These are the vacuum membrane distillation (VMD), direct contact membrane distillation

Manuscript received February 5, 2014; revised April 7, 2014. This work was supported by King Fahd University of Petroleum \& Minerals under project \# IN121043.

Dahiru Umar Lawal is with the Department of Mechanical Engineering, King Fahd University of Petroleum \& Minerals, Dhahran 31261, Saudi Arabia (e-mail: g201201740@kfupm.edu.sa; tel.: +966-50-4646268).

Atia. E. Khalifa is with is with Mechanical Engineering Department, King Fahd University of Petroleum \& Minerals, Dhahran 31261 Saudi Arabia (e-mail: akhalifa@kfupm.edu.sa).
(DCMD), sweeping gas membrane distillation (SGMD) and air gap membrane distillation (AGMD). In all these MD configuration, membrane coefficient (permeability) limit the performance of MD system. Membrane permeability is a function of applied temperature, membrane thickness, pore sizes, tortuosity, porosity, physical properties of fluid, the geometry and its dimension, and the average velocity of the fluid.

In DCMD, evaporation occurs at the hot feed solution when the vapour pressure at the hot side is greater than the vapour pressure at the coolant side of the membrane. The vapourized gases then passes via the pores of membrane and condensed in the flowing coolant solution.

MD can utilizes waste heat to enhanced mass transfer through a hydrophobic, micro porous membrane material. MD operates at low temperature (below boiling point of water). This process was introduced in the late 1960s but has not yet gets to the commercial market. Perhaps, this is due to lack of membranes that have the characteristics most suitable for the process performance, especially at reasonable prices [3].

MD offer some advantages over other desalination techniques like reverse osmosis (RO). The advantages includes but not limited to [4]; (a) Low energy consumption (b) Membrane fouling in MD is less of a problem (c) Lower operating temperatures (temperature as low as $30^{\circ} \mathrm{C}$ have been used) (d) High rejection factors achieved (e) No Extensive pre-treatment is necessary as required in reverse osmosis (f) Possibility of using waste heat and renewable energy. However, MD have some shortcoming which may include: (a) Lack of membranes and modules designed specifically for MD (b) Permeate flux decay with time due to fouling, membrane deterioration (c) Risk of membrane pore wetting (d) Commercial membrane modules are still expensive.

L. Martinez and F. J. Florido Diaz [5] developed a model which is based on a dusty gas model of gas transport through porous media. A direct contact membrane distillation experiment was conducted using two flat sheet membrane material. Two experiment were carried out, in the first experiment, GVHP22 membrane was used while HVHP45 membrane material was employed in the second experiment. The output results show that the developed model prediction were in good agreement with the experimental results.

Jian-Mei Li et al. [6] investigated experimentally the influence of feed flow and feed temperature on distil pure water flux in direct contact membrane distillation (DCMD) and vacuum membrane distillation (VMD) using an aqueous solution of about $35 \mathrm{~g} / \mathrm{l} \mathrm{NaCl}$. Different types of membrane material were compared and there result shows that for both DCMD and VMD, Polyethylene (PE) membrane material produces higher water flux when compared to 
polypropylene (PP) membrane material.

Robert W. Field et al. [7] developed a model for the overall mass transfer coefficient for direct contact membrane distillation. The developed models revealed that membrane effective thickness is the sum of the actual thickness. Their investigation revealed that at a typical conditions, the sum of the additional terms exceeds $100 \mu \mathrm{m}$, which shows that the flux is not inversely proportional to membrane thickness. The sum of the additional terms depends on the heat-transfer coefficients of the films but typically exceeds $100 \mu \mathrm{m}$. They also shows that the thermal efficiency does not depend on membrane thickness. The traditional method for combining the Knudsen diffusion coefficient and the molecular diffusion coefficient overestimates the resistance and at the same time underestimates the permeate flux.

Tzahi Y. Cath et al. [8] experimentally investigate a new membrane module and new membrane distillation configurations. In a turbulent flow regime and with a feed water temperature of only $40{ }^{\circ} \mathrm{C}$, the performances of three hydrophobic micro porous membranes were evaluated. Result revealed that reduction in temperature polarization and permeability obstructions in the DCMD of salt solutions could be obtained simultaneously by careful design of a membrane module and configuration of the MD system. Result shows that there was a substantial improvement in mass transfer of water vapour for the new method as compared to that of the available literature. It was shown that the permeate flux obtained for the new approach can be more than twice of the traditional mode of DCMD when operating at relatively low temperatures. In investigating the performance of the new configuration, both $\mathrm{NaCl}$ and synthetic sea salt feed solutions were used. Salt rejection was greater than $99.9 \%$ in all the cases. Economic aspects of the improved DCMD process was discussed and the new enhanced DCMD process was compared with the reverse osmosis (RO) process for desalination.

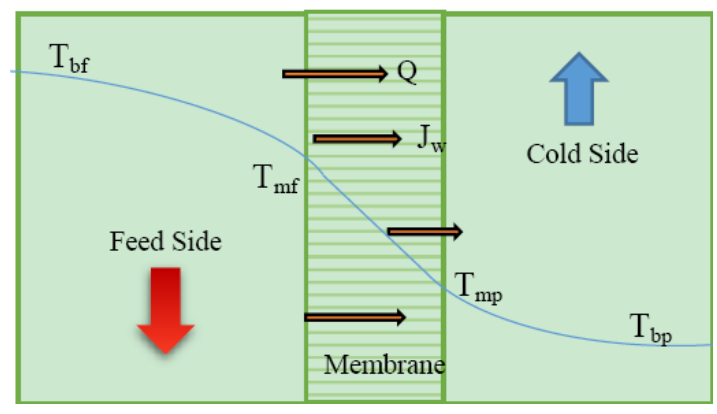

Fig. 1. Schematic diagram of Heat and mass transfer across MD membrane.

\section{THEORY}

The system considered in this study is as depicted in Fig. 1. It consists of feed chamber and coolant chamber separated by a hydrophobic porous membrane material. In this system (DCMD), heat and mass transfer occurs simultaneous. The feed temperature $T_{b f}$ decrease over the feed side boundary layer to $T_{m f}$ at the membrane surface. Part of the water evaporates and diffuse through membrane pores. At the same time, heat is conducted through membrane to the cold chamber. The cold flow temperature $T_{b p}$ rises across the cold boundary layer to $T_{m p}$ at the membrane surface to the cold chamber as vapour condenses into the fresh water [2]. The driving force is hence the vapour pressure difference between $T_{m f}$ and $T_{m p}$, which is less than the vapour pressure difference between $T_{b f}$ and $T_{b p}$. The process is otherwise called temperature polarization [9].

\section{A. Mass Transfer}

Mass transfer in MD takes place by convection and diffusion of vapour through the micro porous membrane sheet [10]. In DCMD, both heat and mass transfer process takes place through the membrane as shown in figure1. The water permeate flux $\left(J_{w}\right)$ obtained depends on the membrane characteristic and the established driving force.

The mechanism of mass transfer in the membrane pores is guided by three basic process. These are the Knudsendiffusion $(K)$, Poiseuille-flow $(P)$ and Molecular-diffusion $(M)$ or a combination between them known as the transition mechanism. The general expression for mass transfer in MD is [11];

$$
\begin{gathered}
J_{W} \propto \Delta P_{m} \\
J_{W}=C_{w} \Delta P_{m}
\end{gathered}
$$

where $C_{w}$ is the overall mass transfer coefficient (membrane permeability) which is the reciprocal of an overall mass transfer resistance and $\Delta P_{m}=P_{m f}-P_{m p}$ is the transmembrane vapour pressure difference (the driving force).

$$
J_{W}=C_{w}\left(P_{m f}-P_{m p}\right)
$$

For pure water, $P_{m}$ is determined by Antione equation [2];

$$
P_{m}=\exp \left(23.328-\frac{3841}{T_{m}-45}\right)
$$

Khayet et al. [12] suggested that the permeate flux has a linear relation with the partial pressure difference through the membrane pores when the feed is water and the temperature difference through the membrane is low.

The Partial pressure difference is obtained as;

$$
P_{m f}-P_{m p}=\left(\frac{d P}{d T}\right)_{T_{m}}\left(T_{m f}-T_{m p}\right)
$$

Substitution of Eq. (3) into (2) leads to

$$
J_{W}=C_{w}\left(\frac{d P}{d T}\right)_{T_{m}}\left(T_{m f}-T_{m p}\right)
$$

where $P_{m f}$, and $P_{m p}$, are the transmembrane vapour pressure at the feed and permeate sides respectively while $T_{m f}$ and $T_{m p}$ are the transmembrane temperature at the feed and permeate sides respectively.

Combination of Clausius-Clapeyron equation and the Antoine equation gives the expression for evaluating $\frac{d P}{d T} \quad[2]$;

$$
\left(\frac{d P}{d T}\right)_{T m}=\frac{\Delta H_{v}}{R T_{m}^{2}} \exp \left(23.328-\frac{3841}{T_{m}-45}\right)
$$


and

$$
\Delta H_{v}=1.7535 T+2024.3
$$

where $R$ is the gas constant equivalent to $8.314472 \mathrm{~J} / \mathrm{mol} . \mathrm{K}$, $T_{m}$ is the mean temperature in kelvin $(k)$ given by $T_{m}=$ $\frac{T_{m f}+T_{m p}}{2}$ and $\Delta H v$ is the heat of vapourisation of water.

\section{B. Membrane Permeability $\left(C_{W}\right)$}

Just like how Reynolds number is used as a guide line in identifying if a flow is laminar, turbulent and transitional, Knudsen number $\left(K_{n}\right)$ is the governing quantity which provide the guideline in identifying which type of mechanism of mass transfer to be considered under the given experimental condition. Based on kinetic theory of gases, the mechanism for mass transfer through DCMD membrane is by Knudsen model or ordinary molecular diffusion or the poiseuille (viscous) flow model or combination of two or more of the models.

In DCMD, the viscous flow model is usually neglected because both feed and permeate solutions are in direct contact with membrane material under atmospheric. The total pressure is constant at atmospheric leading to negligible viscous kind of flow [10], [13], [14]. Knudsen number is expressed as;

$$
K_{n}=\frac{\lambda_{w}}{d_{p}}
$$

where $\lambda_{w}$ is the mean free path of the water molecule and $d_{p}$ is the pore size (diameter). The mean free path of the water molecule is given by;

$$
\lambda_{w}=\frac{K_{B} T}{\sqrt{2} \pi P_{m}\left(2.641 \times 10^{-10}\right)^{2}}
$$

where $K_{B}$ is the Boltzmann constant, $P_{m}$ is the mean pressure within the membrane pores, $T$ is the absolute mean temperature in the pores (Kelvin).
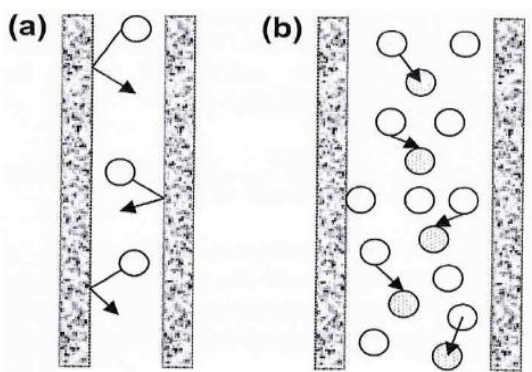

Fig. 2. (a) Knudsen type of flow and (b) Ordinary molecular type of flow [2].

When membrane pore size is low in comparison with mean free path of the water molecules in vapour state $\left(K_{n}>\right.$ 10 or $\left.d_{p}<0.1 \lambda_{w}\right)$, then the molecule-pore wall collisions preside over the molecule-molecule impact, so the Knudsen kind of flow is responsible for the mechanism of mass transfer through the membrane pores as shown in the Fig. 2a. In other word, when the ratio of pore radius to the mean free path is lower than $0.05\left(\frac{r_{p}}{\lambda_{w}}<0.05\right)$, then Knudsen kind of flow model is employed. The membrane permeability $\left(C_{w}^{K}\right)$ in Knudsen region is given as [2], [7], [15], [16];

$$
C_{w}^{K}=\frac{2 \pi}{3} \frac{1}{R T}\left(\frac{8 R T}{\pi M_{w}}\right)^{1 / 2} \frac{r_{k}^{3}}{\tau \delta}
$$

when the membrane pores is assumed to have a uniform size, then the average pore radius is used and it's given as [2], [16], [17];

$$
C_{w}^{K}=\frac{2}{3} \frac{\varepsilon \bar{r}_{k}}{R T \tau \delta}\left(\frac{8 R T}{\pi M_{w}}\right)^{1 / 2}
$$

when the mean free path of the transported water molecules in vapour state is less than the membrane pore size $\left(K_{n}<\right.$ 0.01 or $\left.d_{p}>100 \lambda_{w}\right)$, then the molecule-molecule collision is predominant over the molecule to pore wall, so ordinary molecular diffusion is responsible for the mass transfer in the continuum region which is cause virtually by stagnant air inside the membrane pores due to the low solubility of air in water. In this case, the expression below may be adopted to evaluate the membrane permeability [2], [16];

$$
C_{W}^{D}=\frac{\pi}{R T} \frac{P D_{w}}{P_{a}} \frac{r_{D}^{2}}{\tau \delta}
$$

when the membrane pores is assumed to have a uniform size, then the average pore radius is used and it's given as [2], [16];

$$
C_{W}^{D}=\frac{\varepsilon}{\tau \delta} \frac{P D_{w}}{P_{a}} \frac{M_{W}}{R T}
$$

where $P_{a}$ is the air pressure in the membrane, $P$ is the total pressure inside the membrane pore and $D_{w}$ is the diffusion coefficient which can be determined from the expressions below [2], [4], [17], [18];

$$
\begin{gathered}
P D_{w}=1.895 \times 10^{-5} \mathrm{~T}^{2.072} \\
P D_{w}=1.19 \times 10^{-4} \mathrm{~T}^{1.75} \\
P D_{w}=4.46 \times 10^{-6} \mathrm{~T}^{2.334}
\end{gathered}
$$

where $P D_{w}$ is in $\mathrm{Pa} . \mathrm{m}^{2} / \mathrm{s}$

Transition region occurs when we have $0.01<K_{n}<10$ $\left(0.1 \lambda_{w}<d_{p}<100 \lambda_{w}\right)$. In this case, the molecules of liquid water collides with each other and diffuse through the air molecules. For transition region, combined Knudsen ordinary molecular diffusion type of flow is responsible for the mass transfer. The membrane permeability for this case is determined using the relationship below [2], [16];

$$
C_{w}^{C}=\frac{\pi}{R T} \frac{1}{\tau \delta}\left[\left(\frac{2}{3}\left(\frac{8 R T}{\pi M_{w}}\right)^{\frac{1}{2}} r_{t}^{3}\right)^{-1}+\left(\frac{P D_{w}}{P_{a}} r_{t}^{2}\right)^{-1}\right]^{-1}
$$

when the membrane pores is assumed to have uniform size, then the average pore radius as expressed below is used [2], [16], [17];

$$
C_{w}^{C}=\frac{1}{R T \delta}\left[\frac{3}{2} \frac{\tau}{\varepsilon r}\left(\frac{\pi M_{w}}{8 R T}\right)^{1 / 2}+\frac{P_{a} \tau}{\varepsilon P D}\right]^{-1}
$$

Membrane tortuosity can be estimated using the correlation suggested by Macki-Meares [19]; 


$$
\tau=\frac{(2-\varepsilon)^{2}}{\varepsilon}
$$

where $\varepsilon$ and $\tau$ are the membrane porosity and tortuosity respectively.

\section{Heat Transfer}

Heat transfer in (DCMD) involved three (3) steps as depicted in Fig. 1. The steps are;

Convection heat transfer in the feed boundary layer $\left(Q_{f}\right)$ given by [2];

$$
Q_{f}=h_{f}\left(T_{b f}-T_{m f}\right)
$$

Heat transfer across the membrane sheet $\left(Q_{m}\right)$ which is the summation of latent heat of vaporization $\left(Q_{v}\right)$ and conduction heat transfer through the membrane material and the gas filling pores $\left(Q_{c}\right)$. Hence heat transfer mechanism through membrane is as given in Eq. (16) [2];

$$
Q_{m}=Q_{c}+Q_{v}
$$

where

$$
\begin{gathered}
Q_{V}=J \Delta H v=C_{W}\left(\frac{d P}{d T}\right)_{T_{m}}\left(T_{m f}-T_{m p}\right) \Delta H_{v} \\
Q_{C}=-K_{m} \frac{d T}{d X}=\frac{K_{m}}{\delta}\left(T_{m f}-T_{m p}\right)
\end{gathered}
$$

Combining Eqs. ((16), (17) and (18)) leads to

$$
Q_{m}=\left(\frac{K_{m}}{\delta}+C_{W}\left(\frac{d P}{d T}\right)_{T_{m}} \Delta H_{v}\right) \Delta T_{m}
$$

where $\Delta T_{m}=T_{m f}-T_{m p}$

Heat transfer in the permeate boundary layer $\left(Q_{p}\right)$ which is given by;

$$
Q_{p}=h_{p}\left(T_{m p}-T_{b p}\right)
$$

Different models has been employed in estimating thermal conductivity of the membrane material, but the following sets of equation is often employed [2];

$$
K_{m}=\varepsilon K_{g}+(1-\varepsilon) K_{p}
$$

The Isostress model is used in most of MD studies and is known to gives better estimation of $K_{m}$ [2], [17];

$$
K_{m}=\left[\frac{\varepsilon}{K_{g}}+\frac{(1-\varepsilon)}{K_{p}}\right]^{-1}
$$

where $K_{p}$ and $K_{g}$ are the thermal conductivity of the membrane material and that of the gas filling the membrane pores respectively.

At steady state, the overall heat transfer through the DCMD system is express as shown below;

$$
Q=Q_{f}+Q_{m}+Q_{p}
$$

Combination and manipulation of Eqs (15) to (20) leads to;

$$
\begin{gathered}
T_{m f}=\frac{\frac{K_{m}}{\delta}\left(T_{b p}+\frac{h_{f}}{h_{p}} T_{b f}\right)+h_{f} T_{b f}-J_{w} \Delta H_{v w}}{\frac{K_{m}}{\delta}+h_{f}\left(1+\frac{K_{m}}{\delta h_{p}}\right)} \\
T_{m p}=\frac{\frac{K_{m}}{\delta}\left(T_{b f}+\frac{h_{p}}{h_{f}} T_{b p}\right)+h_{p} T_{b p}+J_{w} \Delta H_{v w}}{\frac{K_{m}}{\delta}+h_{p}\left(1+\frac{K_{m}}{\delta h_{f}}\right)}
\end{gathered}
$$

Heat transfer coefficients $\left(h_{f}\right.$ and $\left.h_{p}\right)$ can be estimated by means of dimensionless Nusselt numbers given by [15];

$$
N u_{i}=\frac{h_{i} d_{i}}{k_{i}} \quad \text { where } i=f, p
$$

where $k$ is the thermal conductivity of the fluid, $d$ is the hydraulic diameter, $h$ is the heat transfer coefficient and $f$ is the feed and $p$ is the permeate.

For laminar flow, the following empirical correlation can be used [19], [20];

$$
N u=1.86\left(\operatorname{Re} \operatorname{Pr} \frac{d}{L}\right)^{0.33}
$$

For turbulent flow correlation below may be used [21];

$$
N u=0.023 \operatorname{Re}^{0.8} \operatorname{Pr}^{0.33}\left(\frac{\mu}{\mu_{S}}\right)^{0.14}
$$

where $\operatorname{Pr}$ and $R e$ are the Prandtl and Reynolds numbers respectively and they are given by;

$$
\operatorname{Pr}=\frac{\mu C_{P}}{k}, \quad \operatorname{Re}=\frac{\rho u d}{\mu}
$$

where $C_{P}, \rho, u$, and $\mu$ are the specific heat capacity, density, average velocity and viscosity of the liquid respectively.

For feed solution containing dissolve salt, $P_{m f}$ may be estimated using the Raoult's law which is given as [22];

$$
P_{m f}=\left(1-C M_{N a c l}\right) P_{m}
$$

where $C M=$ mole solute concentration.

\section{Procedure for Flux Prediction $\left(J_{W}\right)$}

For flux prediction, an iterative method was adopted. Guessed values were assumed for membrane surface temperatures $\left(T_{m f}\right.$ and $\left.T_{m p}\right)$ as initial guess, the guessed values were then utilized to estimate permeate flux $\left(J_{W}\right)$ as given in Eqs. ((4), (5), (6), (9), (11) and (14)). The current flux (Jw) value is then utilized to estimate heat transfer coefficient at average membrane surface temperatures $\left(\frac{T_{b f}+T_{m f}}{2}\right.$ and $\left.\frac{T_{m p}+T_{b p}}{2}\right)$ in accordance with Eqs. ((26)-(28)). Eqs. $((24)$ and (25)) is then used to estimate the membrane surface temperature, the output results was compared with the initial assumed (guessed) values of membrane surface temperature. The above procedures was repeated until the difference between assumed membrane surface temperature and calculated one is less than $0.1 \%$ (until the assumed values for $T_{m f}$ and $T_{m p}$ concurred with the calculated ones 
with the relative error of less than $0.1 \%$ ).

\section{RESULTS AND DiSCUSSIONS}

Prediction of permeate flux was conducted using developed Matlab codes. The results obtained were validated against the experimental work of T.Y. Cath et al. [8] and O. Andrjesdóttir et al. [23] to testify the best theoretical model to be employed in DCMD under the given experimental conditions. Results of prediction for different models of membrane permeability were depicted in Figs. 37.

TABLE I: MEMBRANE PROPERTIES AND GEOMETRICAL CONSTANT USED [8], [23]

\begin{tabular}{l|l|l}
\hline \hline \multirow{2}{*}{ Symbol } & \multicolumn{2}{|c}{ Values as used in } \\
\cline { 2 - 3 } & {$[8]$} & {$[23]$} \\
\hline \hline$\delta$ & $175 \mu \mathrm{m}$ & $140 \mu \mathrm{m}$ \\
$\varepsilon$ & 0.7 & 0.88 \\
$K g$ & $0.029 \mathrm{~W} / \mathrm{mK}$ & $0.029 \mathrm{~W} / \mathrm{mK}$ \\
$K p$ & $0.259 \mathrm{~W} / \mathrm{mK}$ & $0.259 \mathrm{~W} / \mathrm{mK}$ \\
$d_{p}$ & $0.45 \mu \mathrm{m}$ & $0.20 \mu \mathrm{m}$ \\
$R$ & $8.314 \mathrm{~J} / \mathrm{Kmol}$ & $8.314 \mathrm{~J} / \mathrm{Kmol}$ \\
$L$ & $200 \mathrm{~mm}$ & $120 \mathrm{~mm}$ \\
$W$ & $2 \mathrm{~mm}$ & $104 \mathrm{~mm}$ \\
$H$ & $3 \mathrm{~mm}$ & $5.2 \mathrm{~mm}$ \\
$A$ & $6 \times 10^{-4} \mathrm{~m}^{2}$ & $5.408 \times 10^{-4} \mathrm{~m}^{2}$ \\
$d_{h}$ & $2.4 \times 10^{-3} \mathrm{~m}$ & $9.905 \times 10^{-3} \mathrm{~m}$ \\
\hline \hline
\end{tabular}

For a given pore size, only one type of flow model is good for flux prediction. So we cannot assumed that all the three models of mass transfer coefficient can be utilized simultaneously for a given pore size. The minimum and maximum temperature considered in this work are $15{ }^{\circ} \mathrm{C}$ and $60{ }^{0} \mathrm{C}$ respectively. The estimated mean free path for water molecules in vapour phase at these temperatures are $1.27 \times$ $10^{-7} \mathrm{~m}$ and $1.49 \times 10^{-7} \mathrm{~m}$ respectively. For the given pore sizes of $2 \times 10^{-7} \mathrm{~m}$ as used by $\mathrm{O}$. Andrjesdottir et al. [23] and $4.5 \times 10^{-7} \mathrm{~m}$ as employed by $\mathrm{T}$. Y. Cath [8], the Knudsen number were found to be 0.281 and 0.745 respectively.

The obtained $K_{n}$ revealed that the flow in DCMD is described by transition model $\left(0.01<K_{n}<10\right)$ since $K_{n}$ values falls within the transition region. As such we expect combined Knudsen-molecular diffusion kind of flow model to gives most accurate prediction of flux.

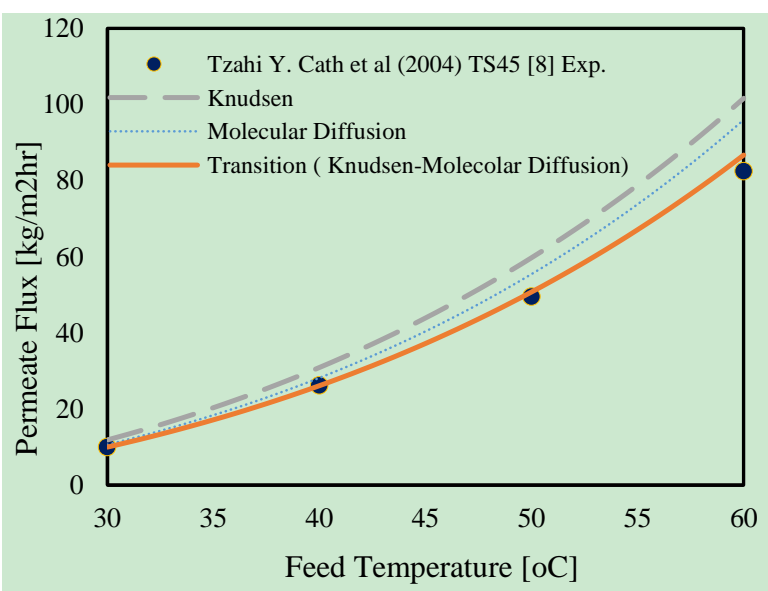

Fig. 3. Flux vs. feed temperature in DCMD for the three models and experimental [8]. Coolant temperature is kept at $20^{\circ} \mathrm{C}$, feed and permeate velocities are $1.75 \mathrm{~m} / \mathrm{s}$.

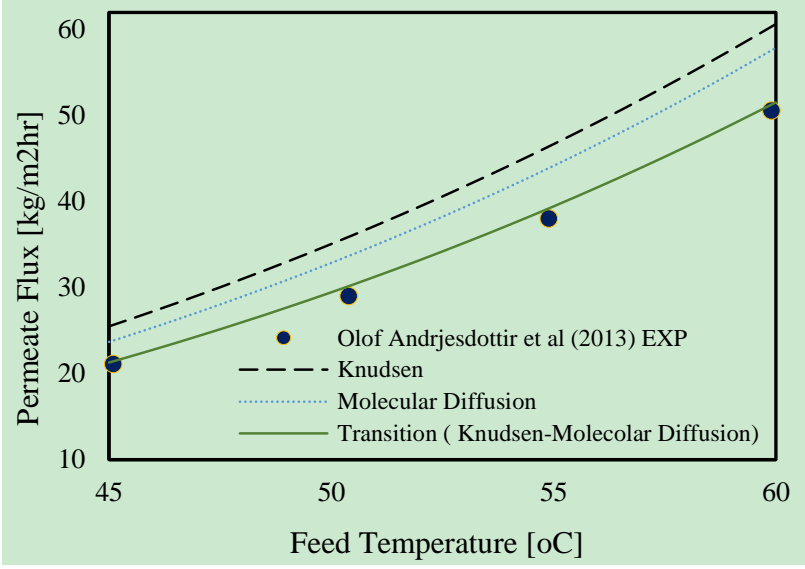

Fig. 4. Flux vs. feed temperature in DCMD for the three models and experimental [23]. Coolant temperature is kept at $21{ }^{\circ} \mathrm{C}$, feed flow rate is 12 $\mathrm{L} / \mathrm{min}$ and coolant flow rate is $4 \mathrm{~L} / \mathrm{min}$.

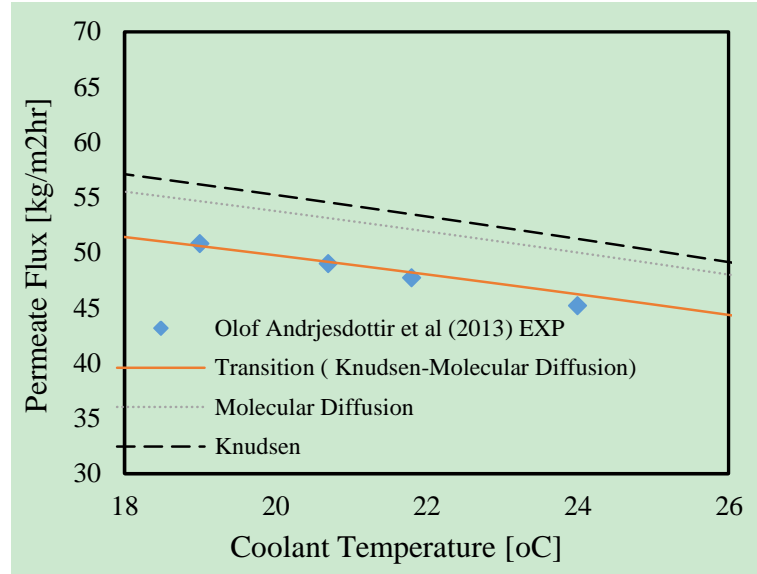

Fig. 5. Effect of coolant temperature on flux for the three models and experimental [23]. Feed temperature is kept at $60{ }^{\circ} \mathrm{C}$, feed flow rate is 12 $\mathrm{L} / \mathrm{min}$ and coolant flow rate is $4 \mathrm{~L} / \mathrm{min}$.

To support the above claim, the developed code was used to predict the permeate flux, the predicted flux were validated against the experimental work of T. Y. Cath et al. [8] and O. Andrjesdottir et al. [23] as shown in Figs. (3, 4, 5 and 6) which depicted the effects of increasing feed temperature, coolant temperature and feed flow rate respectively. Results shows good agreement between transition model prediction and experimental results of [23] and [8].

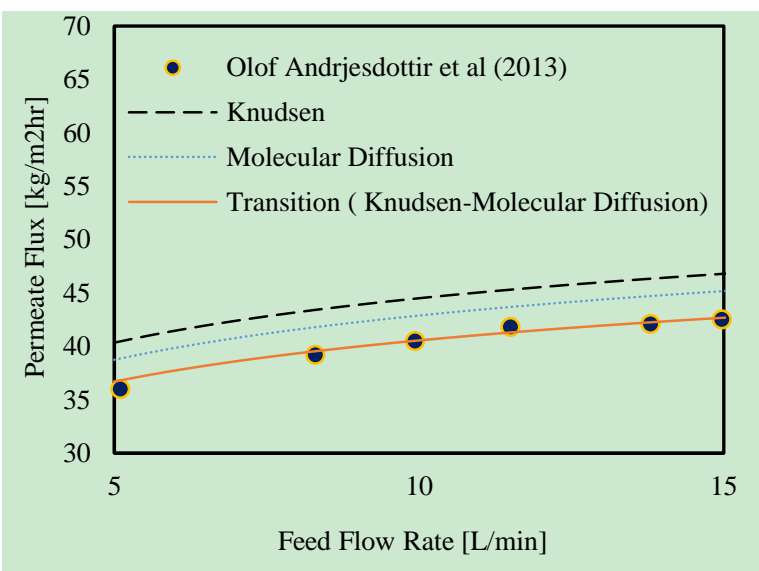

Fig. 6. Effect of flow rate on flux for the three models and experimental [23]. Coolant flow rate is $3 \mathrm{~L} / \mathrm{min}$, feed temperature is $60^{\circ} \mathrm{C}$, and coolant temperature is $21^{\circ} \mathrm{C}$. 


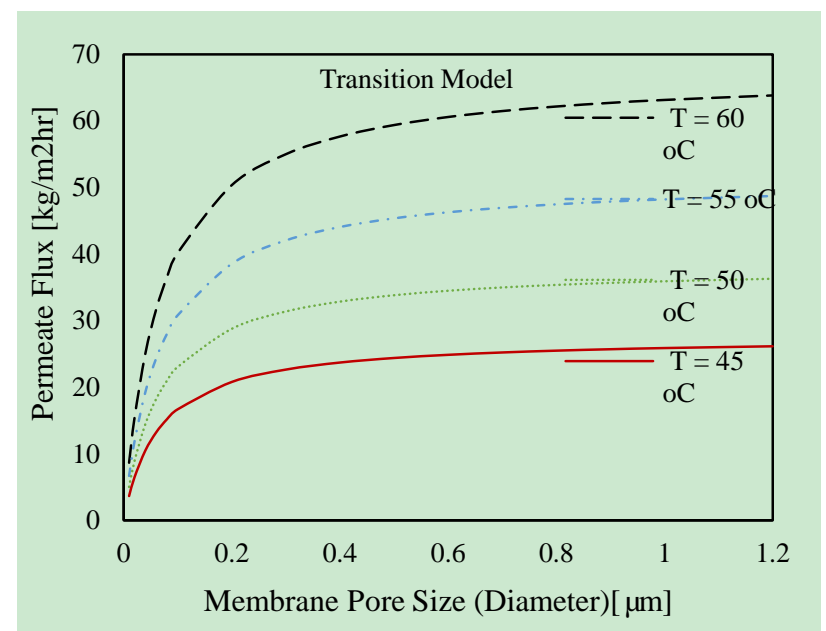

Fig. 7. Effect of pore size in DCMD for combined Knudsen-Molecular diffusion model. Coolant temperature is kept at $21{ }^{\circ} \mathrm{C}$, feed flow rate is 12 $\mathrm{L} / \mathrm{min}$ and coolant flow rate is $4 \mathrm{~L} / \mathrm{min}$.

As observed from Figs. 3, 4, 5 and 6, both the Knudsen diffusion model and molecular diffusion model tends to overestimate the permeate flux with Knudsen type of flow model having the highest flux prediction.

Effect of feed temperature on permeate flux was as shown in Figs. 3 and 4. Permeate flux increases with increase in feed temperature. This is in accordance with Antoine equation which shows exponential rise in vapour pressure as the feed temperature increases. This leads to increase in flux production. It can be concluded that the theoretical model used in this study is good in predicting the permeate flux as there is good agreement between the model predictions and experimental results with an error between $0.1-4.84 \%$ for [8] and $0.47-3.55 \%$ for [23]. Molecular diffusion model is second in flux prediction follow by the Knudsen model when they are compare in terms of good agreement with experimental data.

Fig. 5 depicted the effect of increasing coolant temperate for the three models of membrane coefficient. As observed from the figure, the flux prediction decreases with increase in coolant temperature. This is due to the fact that as the coolant temperature increases, there is decreases in the temperature difference between the feed and the coolant chambers which leads to the reduction of permeate flux. The models prediction shows that Knudsen model gives the highest permeate flux prediction (over prediction). Next in flux prediction model closer to the experimental value is the molecular diffusion model. The transition model gives the best predictions against the experimental values with a deviation ranging between $0.20-2.16 \%$.

Fig. 6 showed the prediction of permeate flux under the influence of feed flow rate. It is seen that flux increases with increase in feed flow rate. This is as a result of higher turbulent that is generated in the feed channel which accelerate higher mixing effect and thus higher flux. The transition models prediction shows good match with experimental data with a minimum deviation ranging from $0.0 \%$ to maximum deviation of $0.96 \%$. The molecular diffusion and Knudsen type of flow model tends to over predict the permeate flux.

To investigate the effect of membrane pore size, membrane pore size were varied from $0.05 \mu \mathrm{m}$ to $1.2 \mu \mathrm{m}$ for different feed temperature using transition model. The selected range of pore size was based on summarized table of commercial membranes commonly used in MD studies [2]. The obtained results was as depicted in Fig. 7. It is obvious from the figure that permeate flux increases with increase in membrane pore size. For instance, for $55^{\circ} \mathrm{C}$ feed temperature, there was an initial sharp rise in permeate flux from $0.01 \mu \mathrm{m}$ to $0.4 \mu \mathrm{m}$. Further increase in pore size resulted in negligible or little increase in permeate flux. The rise in permeate flux continue to diminishes as the pore size increase until the critical pore size $\left(0.1 \lambda_{w}\right)$ where the predicted flux remain constant for any further increment in pore size.

M. Khayet and T. Matsuura [2] stated that to achieve higher permeate flux under some given experimental condition, membrane with pore size smaller than $0.1 \lambda_{w}$ should be used so that Knudsen type of flow will occur which usually gives higher permeate flux.

\section{Conclusions}

The basic concept of heat and mass transfer analysis been performed to evinced the significant effect of membrane permeability (coefficient) on the mass transfer (permeate flux) in DCMD. The presented models was tested on the effect of increasing feed temperature, feed flow rate and coolant temperature. The predicted flux was validated against the experimental work of T. Y. Cath et al. [8] and Olof Andrjesdottir et al. [23]. For DCMD, Knudsen diffusion, molecular diffusion and combine Knudsenmolecular diffusion models may be used in prediction of permeate flux. In model selection, membrane pore size must be taken into consideration. In most cases, the transition model is adopted for the prediction of flux in DCMD since large portion of membrane area is described by transition model.

Results showed that for membrane pore size of 0.2 and $0.45 \mu \mathrm{m}$, transition model is best to be adopted as its flux prediction in all of the cases were in good agreement with the experimental results. Results also revealed that other models for membrane permeability (Knudsen diffusion model and molecular diffusion model) tends to over predict the permeate flux with Knudsen model predicting the maximum flux. These leads to the conclusion that the best model for the prediction of permeate flux in DCMD is the combined Knudsen-molecular diffusion model as most of the region is captured by the model. Increasing the membrane pore size leads to an initial sharp rise in permeate flux production up to the critical pore size where the flux remain constant no matter the increment in pore size.

\section{ACKNOWLEDGMENT}

The authors acknowledged the support received from King Fahd University of Petroleum \& Minerals (KFUPM) to complete this work under the funded project \# IN121043.

\section{NOMENCLATURE}

A Cross sectional area $\left[\mathrm{m}^{2}\right]$

$d_{p} \quad$ Pore size $[\mu \mathrm{m}]$

$d_{h} \quad$ Hydraulic diameter $[\mathrm{m}]$

$D$ Diffusion coefficient $\left[\mathrm{m}^{2} / \mathrm{s}\right]$ 

$\begin{array}{ll}h & \text { Heat transfer coefficient }\left[\mathrm{W} / \mathrm{m}^{2} \mathrm{~K}\right] \\ H_{v} & \text { Heat of vapourisation }[\mathrm{kJ} / \mathrm{kg}] \\ J_{w} & \text { Permeate flux }\left[\mathrm{kg} / \mathrm{m}^{2} \mathrm{hr}\right] \\ K & \text { Thermal conductivity }[\mathrm{W} / \mathrm{mK}] \\ B_{w} & \text { Mass transfer coefficient }\left[\mathrm{kg} / \mathrm{m}^{2} \mathrm{sPa}\right] \\ K_{m} & \text { Membrane thermal conductivity }[\mathrm{W} / \mathrm{mK}] \\ K_{g} & \text { Thermal conductivity of gas filling the pores } \\ {[\mathrm{W} / \mathrm{mK}]} & \end{array}$

$K_{p} \quad$ Thermal conductivity of membrane material $[\mathrm{W} / \mathrm{mK}]$

$K_{n} \quad$ Knudsen number [dimensionless number]

$M_{w} \quad$ Molecular weight $[\mathrm{g} / \mathrm{mol}]$

$\mathrm{Nu} \quad$ Nusselt Number [dimensionless number]

$P \quad$ Total pressure $[\mathrm{Pa}]$

$\mathrm{Pm}$ Mean Pressure $[\mathrm{Pa}]$

$\mathrm{Pr} \quad$ Prandtl Number [dimensionless number]

Qs Sensible heat transfer $\left[\mathrm{W} / \mathrm{m}^{2}\right]$

Qv Latent heat transfer $\left[\mathrm{W} / \mathrm{m}^{2}\right]$

Qc Conduction heat transfer $\left[\mathrm{W} / \mathrm{m}^{2}\right]$

$R \quad$ Gas constant [J/Kmol]

$R e \quad$ Reynolds number [dimensionless number]

Sc Schmidt number [dimensionless number]

Sh Sherwood number [dimensionless number]

$T \quad$ Absolute temperature $[\mathrm{K}]$

Subscripts and Superscripts:

$f \quad$ Feed

$p \quad$ Permeate

$m$ Membrane

$b \quad$ Bulk

$m f \quad$ Feed side of membrane

$m p \quad$ Coolant side of membrane

bf Bulk feed

bp Bulk permeate

$c \quad$ Coolant side

$h$ Hot region

Greek Letters:

$\delta \quad$ Membrane thickness; film thickness $[\mu \mathrm{m}]$

$\varepsilon \quad$ Porosity [\%]

$\tau \quad$ Tortuosity [No unit]

$\mu \quad$ Viscosity $\left[\mathrm{Ns} / \mathrm{m}^{2}\right]$

$\lambda \quad$ Mean free path $[\mathrm{m}]$

$V \quad$ kinematic viscosity $\left[\mathrm{m}^{2} / \mathrm{s}\right]$

$\rho \quad$ Density $\left[\mathrm{kg} / \mathrm{m}^{3}\right]$

\section{REFERENCES}

[1] A. S. Jonsson, R. Wimmerstedt, and A.-C. Harrysson, "Membrane distillation - A theoretical study of evap. through microporous membranes," Desalination, vol. 56, pp. 237-249, 1985.

[2] M. Khayet and T. Matsuura, Membrane distillation principles and applications, Elservier B.V., 2011, ch. 10, pp. 254-268.

[3] A. M. Alklaibi and N. Lior, "Membrane-distillation desalination: status and potential," Desalination, vol. 171, pp. 111-131, March 2004.

[4] R. W. Schofield, A. G. Fane, and C. J. D. Fell, "Gas and vapour transport through micro porous membrane I. Knudsen-Poiseuille transition," Journal of Membrane Science, vol. 53, no. 1-2, pp. 159 171, October 1990.

[5] L. Martínez and F. J. Florido-Díaz, "Theoretical and experimental studies on desalination using membrane distillation," Desalination, vol. 139, no. 1-3, pp. 373-379, September 2001.

[6] J. M. Li, Z. K. Xu, Z. M. Liu, W. F. Yuan, H. Xiang, S. Y. Wang, and Y. Y. Xu, "Microporous polypropylene and polyethylene hollow fiber membranes. Part 3. Experimental studies on membrane distillation for desalination," Desalination, vol. 155, no. 2, pp. 153 156, June 2003
[7] R. W. Field, H. Y. Wu, and J. J. Wu, "Multiscale modeling of membrane distillation:sometheoretical considerations," Industrial \& Engineering Chemistry Research, vol. 52, no. 26, pp. 8822-8828, February 2013.

[8] T. Y. Cath, V. D. Adams, and A. E. Childress, "Experimental study of desalination using direct contact membrane distillation: a new approach to flux enhancement," Journal of Membrane Science, vol. 228, no. 1, pp. 5-16, January 2004.

[9] L. M. Camacho, L. Dumee, J. Zhang, J. Li, M. Duke, J. Gomez, and S. Gray, "Advances in membrane distillation for water desalination and purification application," Water, vol. 5, pp. 94-196, January 2013.

[10] R. W. Schofield, A. G. Fane, and C. J. D. Fell, "Heat and mass transfer in membrane distillation," Journal of Membrane, Science, vol. 33, pp. 299-313, October 1987.

[11] J. Zang, N. Dow, M. Duke, E. Ostarcevic, J. D. Li, and S. Gray, "Identification of material and physical features of membrane Distilation. Membrane for high performance desalination," Journal of Membrane Science, vol. 349, pp. 295-303, March 2010.

[12] M. Khayet, P. Godino, and J. I. Mengual, "Study of asymmetric polarization in direct contact membrane distillation," Separation Science and Technology, vol. 39, pp. 125-147, 2005.

[13] R. W. Schofield, A. G. Fane, and C. J. D. Fell, "Factors affecting flux in membrane distillation," Desalination, vol. 77, pp. 279-294, 1990

[14] R. W. Schofield, A. G. Fane, and C. J. D. Fell, "Gas and vapour transport through micro porous membranes. II. Membrane distillation," Journal of Membrane Science, vol. 53, no. 1-2, pp. 173-185, October 1990

[15] A. Alkhudhiri, N. Darwish, and N. Hilal, "Membrane distillation: A comprehensive review," Desalination, vol. 287 , pp. 2-18, February 2012 .

[16] M. Khayet, A. Velázquez, and J. I. Mengual, "Modelling mass transport through a porous partition: effect of pore size distribution," Journal of Non-Equilibrium Thermodynamics, vol. 29, no. 3, pp. 279-299, September 2004.

[17] J. Phattaranawik, R. Jiraratananon, and A. G. Fane, "Effect of pore size distribution and air flux on mass transport in direct contact membrane distillation," Journal of Membrane Science, vol. 215, pp. 75-85, 2003.

[18] Y. Yun, R. Ma, W. Zhang, A. G. Fane, and J. Li, "Direct contact membrane distillation mechanism for high concentration $\mathrm{NaCl}$ solutions," Desalination, vol. 188, pp. 251-262, April 2005.

[19] S. Srisurichan, R. Jiraratananon, and A. G. Fane, "Mass transfer mechanisms and transport resistances in direct contact membrane distillation process," Journal of Membrane Science, vol. 277, no. 1-2, pp. 186-194, June 2006.

[20] L. Martínez-Díez and M. I. Vázquez-González, "Temperature and concentration polarization in membrane distillation of aqueous salt solutions," Journal of Membrane Science, vol. 156, no. 2, pp. 265 273, 1999.

[21] K. W. Lawson and D. R. Lloyd, "Membrane distillation," Journal of Membrane Science, vol. 124, no. 1, pp. 1-25, February 1997.

[22] M.N.A. Hawlader, R. Bahar, K. C. Ng, and L. J. W. Stanley, "Transport analysis of an air gap membrane distillation (AGMD) process," Desalination \& Water Treatment, vol. 42, pp. 333-346, April 2012.

[23] O. Andrjesdottir, C. L. Ong, M. Nabavi, S. Paredes, A. S. G. Khalil, B. Michel, and D. Poulikakos, "An experimentally optimized model for heat and mass transfer in direct contact membrane distillation," International Journal of Heat and Mass Transfer, vol. 66, pp. 855867, November 2013.

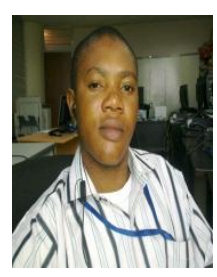

Dahiru U. Lawal is a graduate student at the Mechanical Engineering Department, King Fahd University of Petroleum \& Minerals, Dhahran 31261, Saudi Arabia. Mr. Dahiru earned his Bachelor degree in Mechanical Engineering in 2010. His research interests are in the area of thermo-fluid sciences. Mr. Dahiru had worked in number of companies including; Textile, Communications Companies, and water Treatment Corporation.

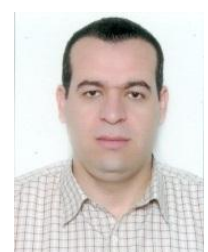

Atia E. Khalifa is an assistant professor in the King Fahd Univ. of Petroleum \& Minerals, Mechanical Engineering Department, P.O. box 1068 Dhahran 31261, Saudi Arabia, PhD 2009. Dr. Khalifa's research areas include Experimental and numerical fluid mechanics, turbo machinery, aerodynamics, combustion, and Desalination. 